This item was submitted to Loughborough's Research Repository by the author.

Items in Figshare are protected by copyright, with all rights reserved, unless otherwise indicated.

\title{
The fastest field sport in the world: A case report on 3-D printed hurling gloves to help prevent injury
}

PLEASE CITE THE PUBLISHED VERSION

http://dx.doi.org/10.1016/j.jht.2017.05.015

\section{PUBLISHER}

(c) Crown. Published by Elsevier

\section{VERSION}

AM (Accepted Manuscript)

\section{PUBLISHER STATEMENT}

This work is made available according to the conditions of the Creative Commons Attribution-NonCommercialNoDerivatives 4.0 International (CC BY-NC-ND 4.0) licence. Full details of this licence are available at: https://creativecommons.org/licenses/by-nc-nd/4.0/

\section{LICENCE}

CC BY-NC-ND 4.0

\section{REPOSITORY RECORD}

Harte, Daniel, and Abby Paterson. 2019. "The Fastest Field Sport in the World: A Case Report on 3-D Printed Hurling Gloves to Help Prevent Injury”. figshare. https://hdl.handle.net/2134/25781. 


\section{The Fastest Field Sport in the World: A Case Report on 3-D Printed Hurling Gloves to Help Prevent Injury}

\section{ABSTRACT}

Study Design: Case Series

Introduction: Hand injuries are the most common injury observed in hurling though compliance in wearing protective gloves is reportedly low.

Purpose: To devise a glove that offers comfort, protection and freedom-of-movement, using the bespoke capabilities of three-dimensional (3D) printing.

Methods: Each player's "catching" hand was imaged using a 3D scanner to produce a bespoke glove that they later trialed and provided feedback.

Results: Nine players provided feedback. On average the players favorably rated the glove for the protection offered. The average response on comfort was poor and no players reported that glove aided performance during play.

Discussion: This feasibility study explores the versatility of 3D printing as a potential avenue to improve player compliance in wearing protective sportswear. Feedback will help refine glove design for future prototypes.

Conclusions: Hurling is the primary focus in this study, but knowledge gains should be transferable to other sports that have a high incidence of hand injury.

Level of Evidence: 4

Keywords

Sport, injury, hand, printing, three-dimensional, protective device 


\section{INTRODUCTION}

Engagement in sport promotes health and well-being but also carries the risk of injury ${ }^{1}$. Hand fractures have been reported as the most common area of injury in sports participation ${ }^{2}$ with phalangeal fractures being the most common, particularly to the first and fifth rays ${ }^{3}$. Football (soccer and Gaelic football) is reportedly the sport that presents with the most hand injuries based on data from an Emergency Department in Scotland over a one-year period ${ }^{3}$. The number of injuries sustained by professional and amateur players was not defined. Injuries to the hand result in the most economic burden and impact on productivity above other injury types ${ }^{4}$.

Sports governed by the Gaelic Athletic Association (GAA) include handball, football, hurling, camogie and rounders. In Gaelic football, ankle injuries are most prevalent ${ }^{5,}{ }^{6}$ though children who participate in Gaelic football more commonly present with hand injuries than lower limb injuries ${ }^{7}$. It has been hypothesized that this is possibly due to the ongoing development of hand-eye co-ordination in the younger player (collision with the ball was the most common mechanism of injury).

Hurling is a field sport played with wooden sticks and a ball, called hurleys, and a slíotar respectively. The hurley is used to strike the slíotar on the ground or into the air. The slíotar can also be passed by hand between players. Each team comprises of 15 players with the object of accruing goals (weighted as three points) under the crossbar of an "H"shaped goal post or one point over its crossbar ${ }^{8}$. Camogie refers to the female variant of the game. Hurling is thought to pre-date Christianity and the sport was standardized by the Gaelic Athletic Association in $1884^{9}$. It has been coined as the "fastest field sport in the world" due to the high velocity the slíotar can achieve during play ${ }^{10}$. Most hand injuries are sustained from being struck by a hurley ${ }^{11}$. The GAA currently have no regulations on glove 
requirements for hurling. The need for protection needs to be carefully weighted with the demands of the sport and comfort. In this regard, commercial hurling gloves offer protection to the dorsal aspect of the hand while the palmar area is mainly exposed for sensory feedback when catching the ball. However, compliance of players wearing protective gloves is often poor due to impeded performance, discomfort and excessive perspiration.

Based on a study of 1030 injuries sustained in hurling, most soft tissue injuries occurred in the lower limb, while fractures presented more in the upper limb ${ }^{12}$. In a smaller study of 163 adults who participate in hurling, upper limb injuries distal to the wrist were the most observed with $38 \%$ of these soft tissue injuries and $68 \%$ fractures. Of these, fractures to the fifth and first rays were most common with the highest incidence to the metacarpal, the proximal phalanx and then the middle phalan $x^{13}$. This reflects similar patterns of injury in another study focusing on hand injuries in hurling ${ }^{14}$. It has been commented that most hurling players do not wear gloves ${ }^{13,14}$. A survey of 163 players shows that it is felt that the bulkiness of gloves results in diminished dexterity essential for handling the slíotar (ball) (75.4\%), that protection from existing gloves is inadequate (58.3\%) and $74.2 \%$ of the players would try a newly designed glove if available ${ }^{13}$. Since the mandatory introduction of head and face protection in hurling, associated injuries to these areas have markedly declined though hand injuries remain common-place ${ }^{11}$. While there have been no studies comparing the incidence of hand injuries between players who wear gloves and those who do not in hurling, a study on the variant sports of lacrosse, field hockey and ice hockey found that there was a significantly higher rate of injury in the ungloved hand ${ }^{15}$. 'Additive Manufacturing' (AM), otherwise known as three-dimensional (3D) Printing, technology is increasingly being explored across many fields of science including aerospace and medicine. In its simplest form, 3D printing is a method of building an object layer by layer ${ }^{16}$. There are many different types of AM/3D Printing technologies; some 
extrude plastic filament (similar to a heated glue gun); some are based on 'curing' lightsensitive resin using a ultra-violet laser (Stereolithography), and others rely on powderbased materials which are either bound together with a high intensity laser to melt powder particles together (Laser Sintering), or adhesives are deposited to bind the powder (Powder binding). There are many others, including PolyJet processes which behave in a similar manner to inkjet printers (but resins are cured with ultra-violet light). Each AM process offers unique strengths and weaknesses, but the view of strength/weakness very much depends on the intended application. One aspect which all processes share is the geometric freedom on offer, and the ability to create almost any 3D form. Given its versatility and ability to create almost anything, AM is ideally suited to making custommade, custom-fitted artifacts ${ }^{17}$. With regards to hand therapy, there are prior examples of printed wrist orthoses ${ }^{18}$, finger mallet orthoses ${ }^{19}$ and robotic dynamic orthoses for postsurgical rehabilitation ${ }^{20}$. In the context of sports, AM has been used to make custom-made wheelchair gloves for paralympians ${ }^{21}$ to improve performance. However, there has been limited development of custom-fitting devices specifically for sports injury prevention.

\section{PURPOSE}

The purpose of this feasibility study was to explore the potential of 3D scanning to produce a bespoke glove for the individual player. The sport analyzed in this instance was hurling. The rationale for this was to address issues associated with poor compliance of hurlers and therefore attempt to design a glove that meets player expectations on comfort, performance and protection. The intention of this project was to assess the suitability of low-cost 3D printing for making custom-made hurling gloves, and to make a range of prototypes for a small cohort in the context of a feasibility study. The findings were intended to establish a means to drive follow-on design specifications, and to establish 
whether 3D printing an entire glove is appropriate, or whether there is a need to mix 3D printing with other fabrication methods to make custom-fitting injury prevention gloves. The following objectives were set:

- Understand the current requirements of the players in terms of what injury prevention is required

- Generate quick, low-cost (i.e. 'low-fidelity') prototypes for review with key stakeholders (mainly, hurling players)

- Generate custom-made sports gloves using 3D printing only

- Analyze and evaluate a range of key criteria, including comfort, durability, and practicality of using 3D Printing as a sole means of fabricating custom-made hurling gloves.

\section{METHODS}

\subsection{Ethics}

This study was conducted in compliance with the Research Governance Framework for Health and Social Care and Good Clinical Practice (GCP). It was conducted in accordance with approvals from the Office of Research Ethics Committees in Northern Ireland and the Southern Health and Social Care Trust Research Governance Committee. Ethical approval was also received from Loughborough University. All participants were given a participant information sheet, and provided written, informed consent. Players consented to photographs being taken and used for the purposes of the study.

\subsection{Study Design}

This study presents a case series on players who trialed a specially designed 3D-printed hurling glove to prevent hand injuries. A questionnaire was devised to collect demographic 
data on each player and to collate their views on the glove. This was completed using a Likert-type questionnaire and open questions.

An iterative design process was followed to develop the glove. This was completed by a hand therapist and industrial designer in academia. The hand therapist had more than ten year's clinical experience and the industrial designer was an academic with eight years experience in Additive Manufacturing/3D Printing. The hand therapist referred to anatomical considerations, a knowledge of the literature on the most common injuries in hurling, and clinical knowledge of orthotics to aid the process of glove design. The industrial designer was able to advise the therapist on the limitations and possibilities of 3D printing. Together, the hand therapist and industrial designer developed illustrations of how the glove would look and what features would be built into it to allow movement and also offer protection.

There were two main phases to the process of creating the gloves themselves (): The first process involved capturing participant scan data of their forearm, wrist and hand. A pilot test of the 3D scanning protocol was performed prior to capturing participant scan data to check the integrity of the scanning protocol; this was performed by the designer, by capturing the hand therapist's shape of the hand.

The second phase was an iterative cyclical process (See Figure 1) which involved a number of stages to take concept designs into suitable formats so they could be 3D Printed. In order to print an object on a 3D Printer, it is first necessary to make a virtual object using Computer Aided Design Software. Therefore, the Second Phase involved Design Planning (Phase 2.1), Computer-Aided Design (CAD) modeling (Phase 2.2), 3D Printing (Phase 2.3), Evaluation (Phase 2.4) and Design Refinement (Phase 2.5). 


\section{Phase 1: Scanning}

Phase 2.1: Design planning

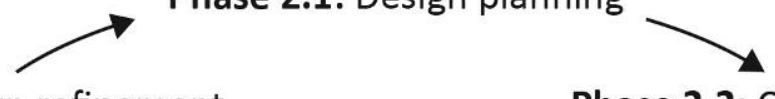

Phase 2.5: Design refinement

Phase 2.2: CAD modelling

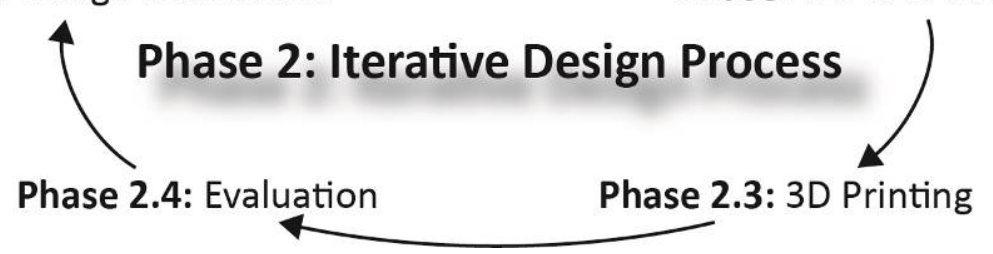

Figure 1: Methodology

Three iterations of this process were undertaken to develop initial low-fidelity prototypes into the final designs;

Iteration 1. A finger glove prototype was made to check the shape and features of the intended glove design characteristics as well as material properties and 3D print parameters.

Iteration 2. A full glove prototype was designed and 3D printed for the hand therapist in light of feedback gained from iteration 1

Iteration 3. A full glove prototype was re-designed in light of comments/feedback from the hand therapist (co-author) in Iteration 2 (Phase 2.3 was overlooked due to lack of time, so feedback was sought via a 3D portable document format (PDF) version of the CAD model).

Iteration 4. Refined design and manufacture of 8 final full glove prototypes, evaluated on intended users 
The final output was a case series on player feedback of a 3D-printed hurling glove to prevent hand injuries. These various iterations will now be described in more detail.

Iteration 1. A finger glove prototype was required in the early stages as it was a quicker, cheaper method of making a prototype than an entire glove which ultimately would have featured a number of repeat shapes for each finger anyway. The finger prototype was made of Ninjaflex - a flexible, low cost, highly durable material - and took 1 hour 13 minutes to make on the 3D Printer (Figure 2).

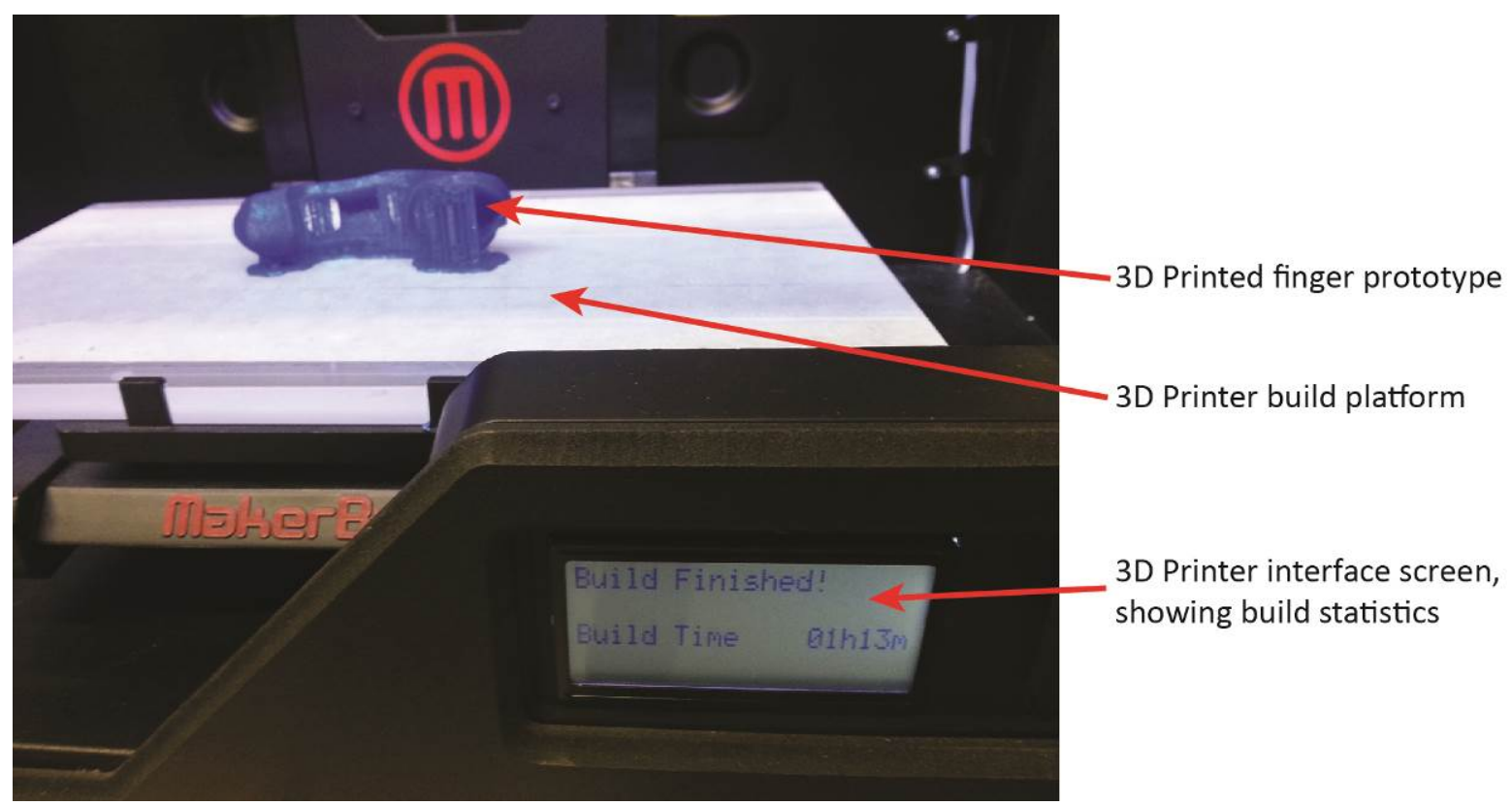

Figure 2: 3D Printer, showing orientation of the 3D Printed finger glove prototype

The finger glove prototype featured a lot of different physical design characteristics which were, conceptually, incorporated to deliberately challenge the ideals of existing hurling glove designs. Figure 3 for example shows some of these design characteristics. Characteristic 'a' (cylindrical anchor points) were added to allow the attachment and removal of armor plates. Characteristic 'b' was a ring-like structure, which kept the prototype firmly attached on the finger. The position of this ring on the finger was crucial; it was imperative that it was not impeding the flexion at the metacarpophalangeal (MCP) joint or the proximal interphalangeal (PIP) joint, otherwise this could have led to chafing and discomfort. Characteristic 'b' worked in collaboration with Characteristic 'c', where the 
tip of the finger was covered by the finger prototype. Again, this was incorporated to challenge existing designs of hurling gloves, which usually left tips of the fingers exposed. The design rationale behind this was that it kept a secure fit onto the finger, whilst providing a hard exterior shell as a form of protection against mallet finger, where a sudden impact can damage the tendon controlling flexion of the distal phalanx at the distal interphalangeal (DIP) joint. Another purpose for adding the finger-tip protection was it provided an opportunity for enhanced grip. Ninjaflex can offer additional traction, so it was conceptualized that this could enhance grip amongst players (particularly with an added texture on the fingertip). Characteristic 'd' was two holes over the finger joints, which allowed flexion. Combined with Characteristic 'e', the intention of leaving these areas 'open' was to allow flexion without the restriction of material covering these joints, as the joints "protrude" as the distal bones move volarly around the joint when flexed. Characteristic 'e' featured two armor plates; one was positioned over the proximal phalanx, whilst the second was positioned over the middle phalanx. They were designed to be detachable in case they became damaged during play, and another armor plate was needed as a replacement. In this context, a replacement armor plate is faster to reproduce than an entire glove with 3D Printing, so localized modification was favorable in this context. Finally, Characteristic 'f' was a gap between the armor plates (Characteristic 'e'), to allow flexion. However, the meeting faces of the two armor plates were designed to meet and 'lock' into place. 


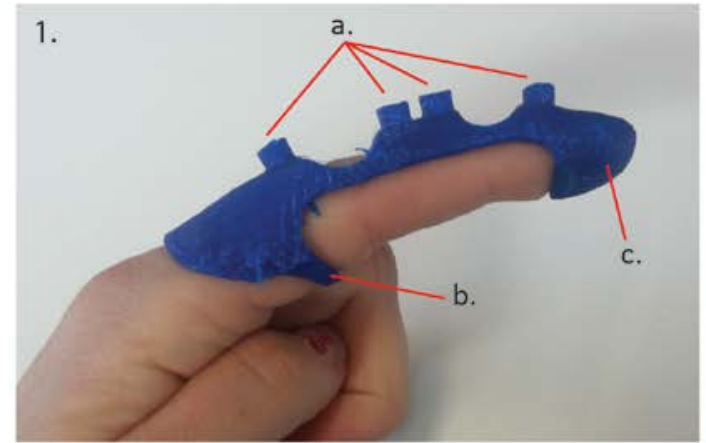

Finger and prototype in extension

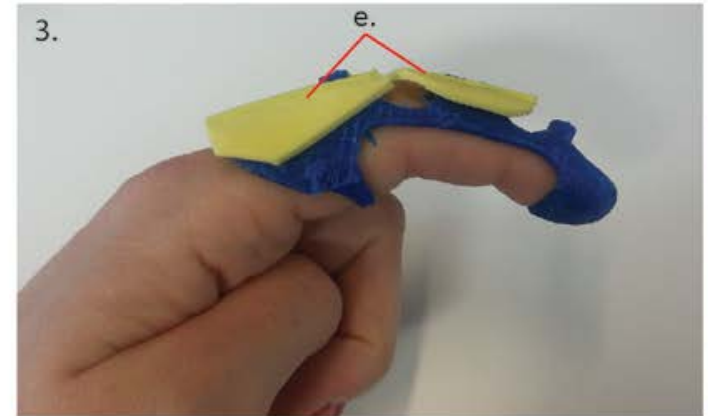

Finger cover in flexion, showing armor for the PP and MP

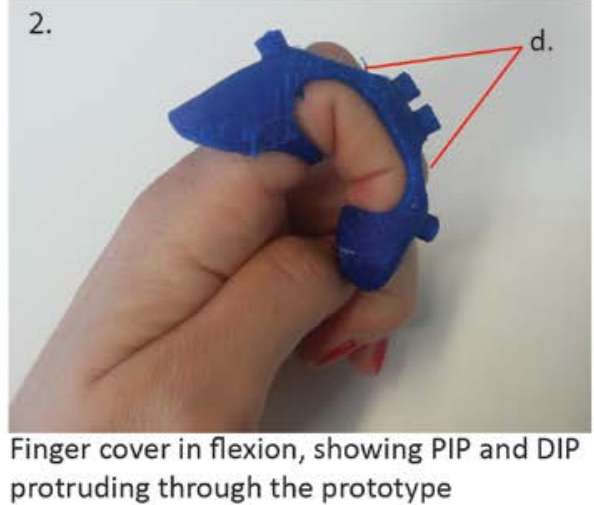

4.

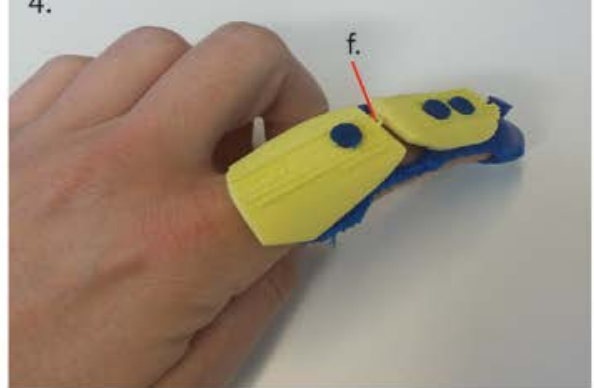

Top view of the finger glove prototype with armor, showing the anchor pins keeping the armour in place.

Figure 3: Finger prototype characteristics. a: anchor points to hold the armor plates (e); b: proximal phalanx (PP) ring, to keep the prototype secure on the finger; c: distal phalanx (DP) tip protector; d: proximal interphalangeal (PIP) and distal interphalangeal (DIP) exposure areas, to enable flexion of the finger and finger protector; e: armor plates, secured with anchor points (a), and; f: space between anchor points, to enable flexion of the finger. MP = Middle Phalanx

The hand therapist obtained feedback from several hurling coaches on the finger prototype prior to the final design phase and recruitment of the players. Whilst they understood the incorporation for having a full cover of the finger, they felt too much coverage of the hand would reduce the sensory feedback necessary to feel the ball when seeking to catch it. Therefore, the design of the follow-on prototypes were amended to take this feedback into account. 


\section{Iteration 2}

Iteration 2 involved the design and fabrication of the whole glove, having addressed feedback received from the first finger prototype. The prototype was designed based on the scan data of the hand therapist, and the intent of a full glove was that the therapist would be able to provide clinical insights in potential issues arising from the design and any restrictions such as grasp as a result of the design and materials used. Figure 4 shows the prototype, which featured many of the same characteristics from the finger splint except for the full finger coverage. The glove was made without armor plates, as the main purpose of this prototype was to assess comfort and identify restrictions in fucntional movement; the armor would not have affected these as the armor was placed on the dorsum of the hand.

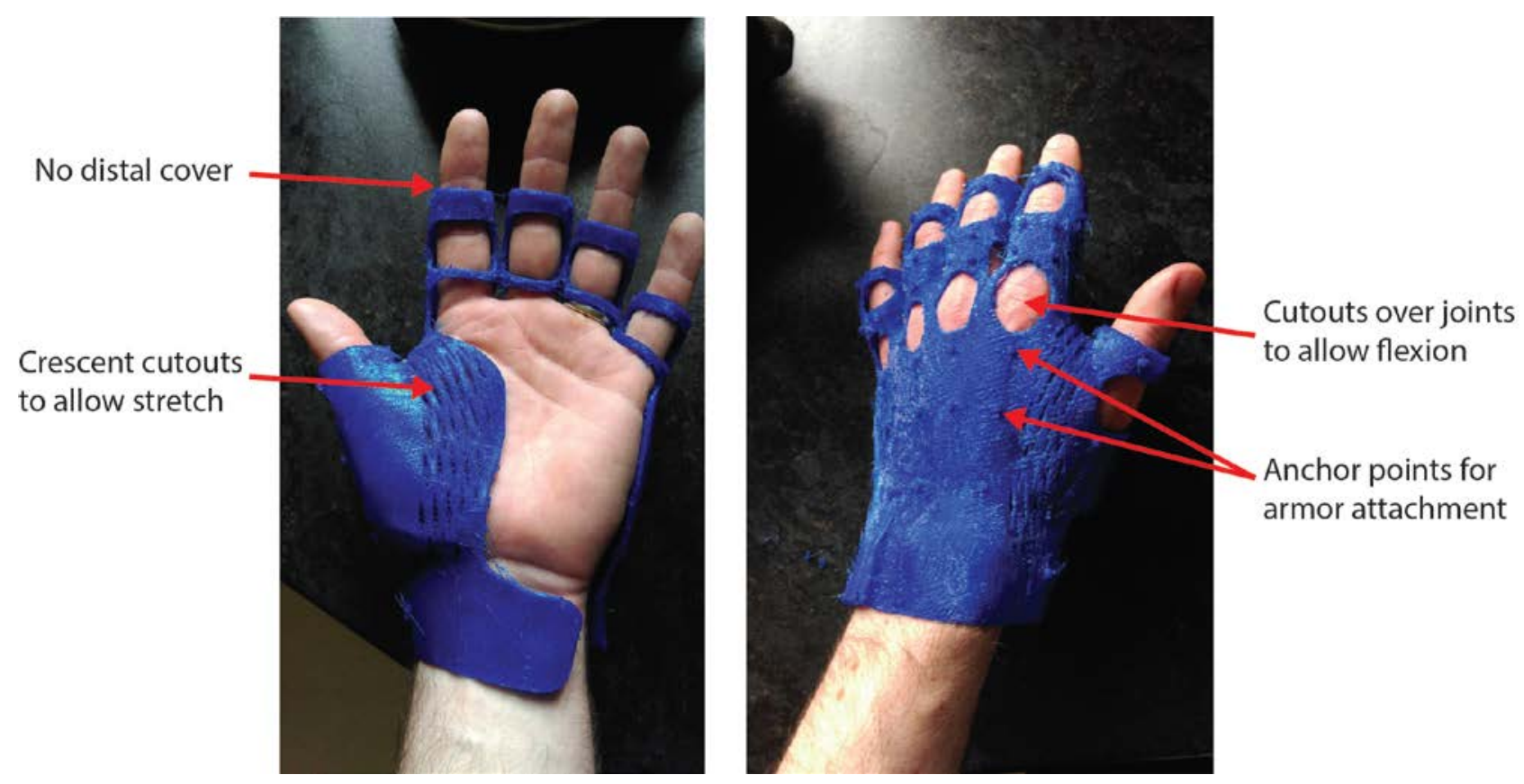

Figure 4: Iteration 2 prototype - full glove custom-made for hand therapist for evaluation

Feedback from the prototypes was sent to the industrial designer via email, with photographs and comments. Suggestions of design changes were noted, for the third design iteration. The therapist felt that their ability to form a fist or vary finger position was 
not impeded. However, the thumb felt restricted, despite having crescent lattice around the thenar region to allow stretch.

\section{Iteration 3}

A third glove design was made in CAD. Due to time restrictions, the glove was not printed but was instead supplied as a 3D portable document format (PDF), so the hand therapist could view a digital copy of the design and suggest improvements. A 3D PDF was vital, as the therapist did not have access to 3D CAD software, so instead a 3D viewer was necessary so they could see all the different characteristics of the model without printing it using a 3D Printer. This time, there were covers over the dorsal PIP joints and MCP joints which would accommodate joint-based armor plates. In addition, the thumb metacarpal armor plate was added. The model also showed armor over all metacarpals, MCP joints, proximal and middle phalanges, and PIP joints.

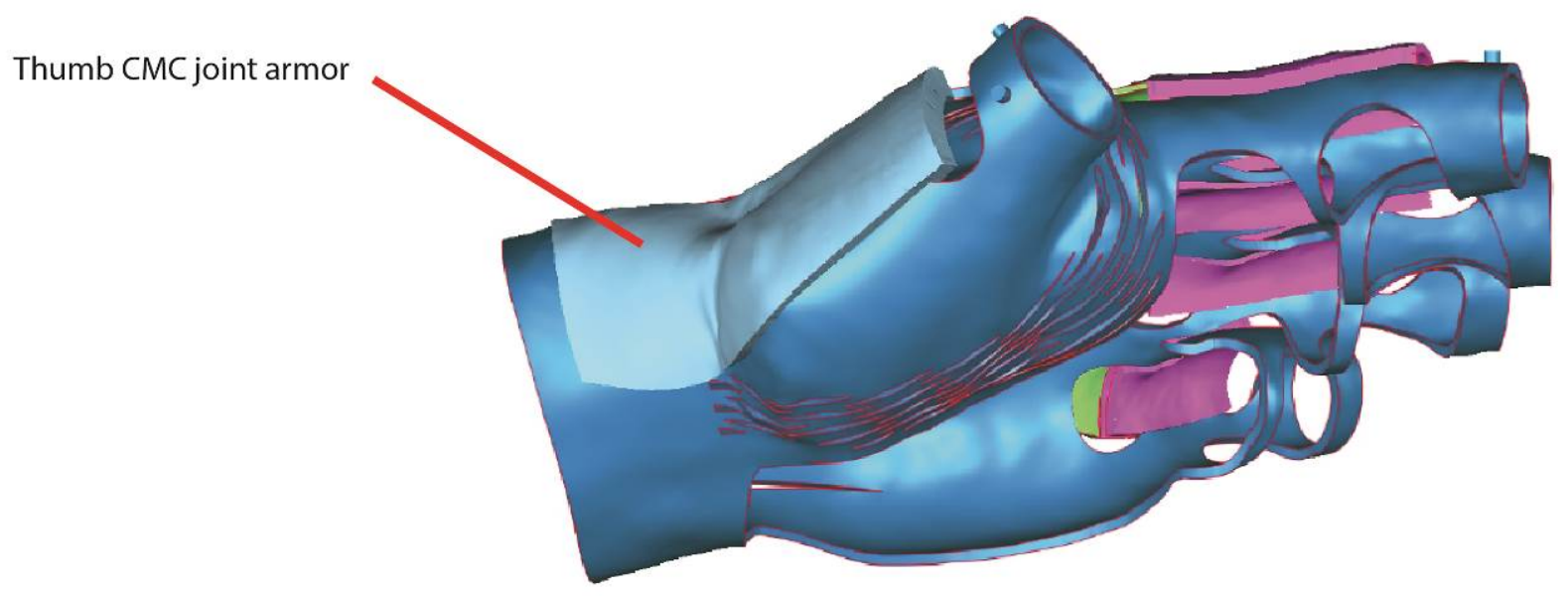

Figure 5: Iteration 3 glove design. $\mathrm{CMC}=$ carpometacarpal

To enable clear communication between the hand therapist and designer, the therapist printed out visual cues on A3 paper of the gloves, and annotated the drawings with proposed changes for the follow-on designs (which would be the intended 'final designs' for the participants of the main study). Some of these visual prints and annotations can be 
seen in Figure 6. Design changes included making the armor over the thumb end at the carpometacarpal joint, and extending the armor around the radial aspect of the 1st metacarpal.

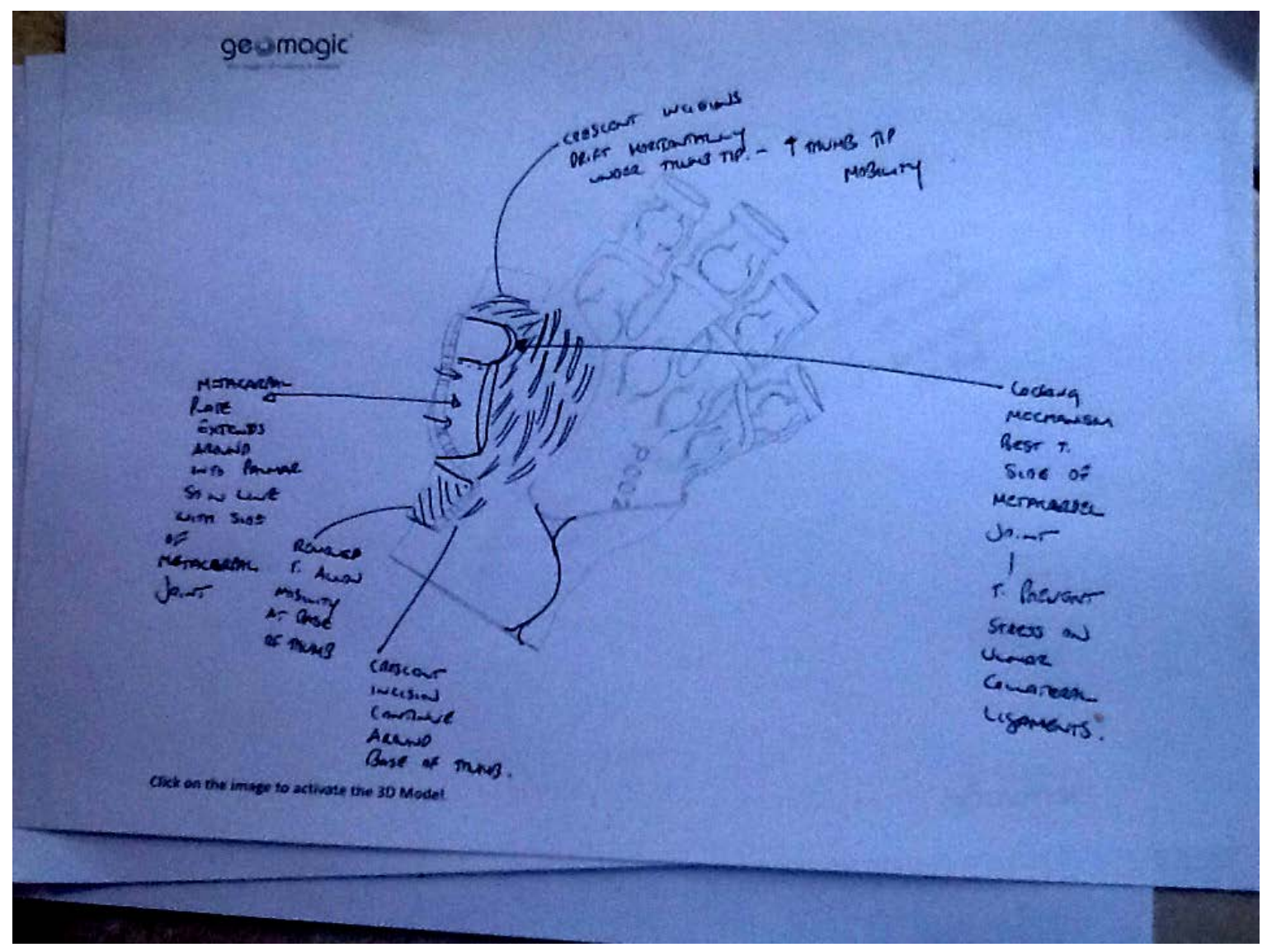

Figure 6: Iteration 3 glove design feedback

\subsection{Recruitment}

Hurling and camogie players were recruited from a local hurling club. The inclusion criteria were that all players were over 18 years of age with at least three years experience playing hurling at a senior level. Players had to be fit to play the sport during the period of the glove trial. The exclusion criteria were players who were less than six months from a significant hand injury i.e. required treatment in an Emergency Department. 


\subsection{Materials}

Two types of 3D printing materials were used on the MakerBot Replicator 2 3D Printer:

- Ninjaflex (Fenner Drives, 311 W. Stiegel Street, Manheim, PA 17545)

- Polylactic Acid (PLA) (MakerBot Industries LLC, One MetroTech Center, Brooklyn, NY).

NinjaFlex was used for the main glove geometry due to its flexibility and high tear resistance. PLA was used due to its strength and rigidity. Both materials along with the 3D Printer were also chosen as collectively they are a low-cost solution for 3D printing, and the materials did not pose any health concerns when the filaments are in their solid state. Other 3D Printing technologies were considered such as Objet Connex PolyJet systems which enable multi-material single builds, but the resins were significantly more expensive and datasheets stated skin irritation could occur if materials were in direct contact with the skin; from a health and safety point of view the investigators chose the lower cost solution.

\subsection{Procedure}

\subsubsection{Concept Development}

The industrial designer produced a series of CAD files to illustrate the glove prior to production of the prototype. Geomagic Studio Version 2012 (3D Systems, Rock Hill, South Carolina, USA) was used on a Windows 7 PC (Dell M6500, 64-bit, i7-Q820, 1.73GHz, 8GB RAM, with AMD ATI FirePro M7740 graphics card) to create the glove designs based on the 3D scan data of each participant.

Characteristic 1. A rigid component is positioned along the radial and dorsal aspect of the proximal phalanx and metacarpal of the thumb with a hinge at the MCPjoint to allow flexion but preventing joint hyperextension and radial deviation of the joint beyond $20^{\circ}$ (Figure 3). The rationale for this is to prevent stress on the ulnar 
collateral ligament at the thumb MCP joint, an anatomical structure that is commonly injured in sports ${ }^{22}$.

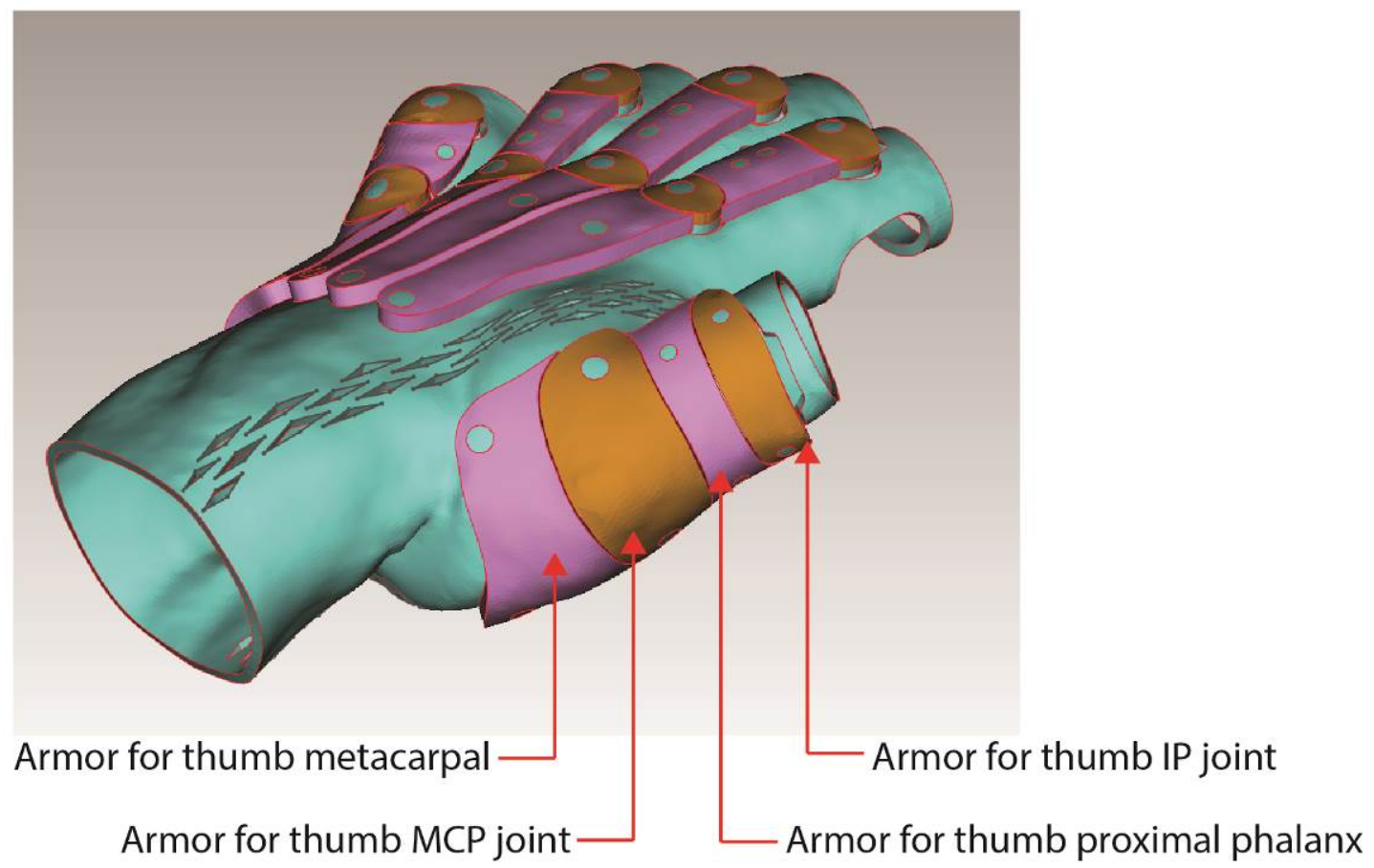

Figure 7: Characteristic 1. MCP =Metacarpophalangeal, IP = Interphalangeal

Characteristic 2. Hinges were positioned at the dorsal aspect of the finger PIP joints to allow for unrestricted flexion but prevent hyperextension (Figures 3 and 4). The rationale for this is that the volar plate ligaments on the volar aspect of the PIP joints are susceptible to tearing with forced hyperextension of the joints ${ }^{23}$. 

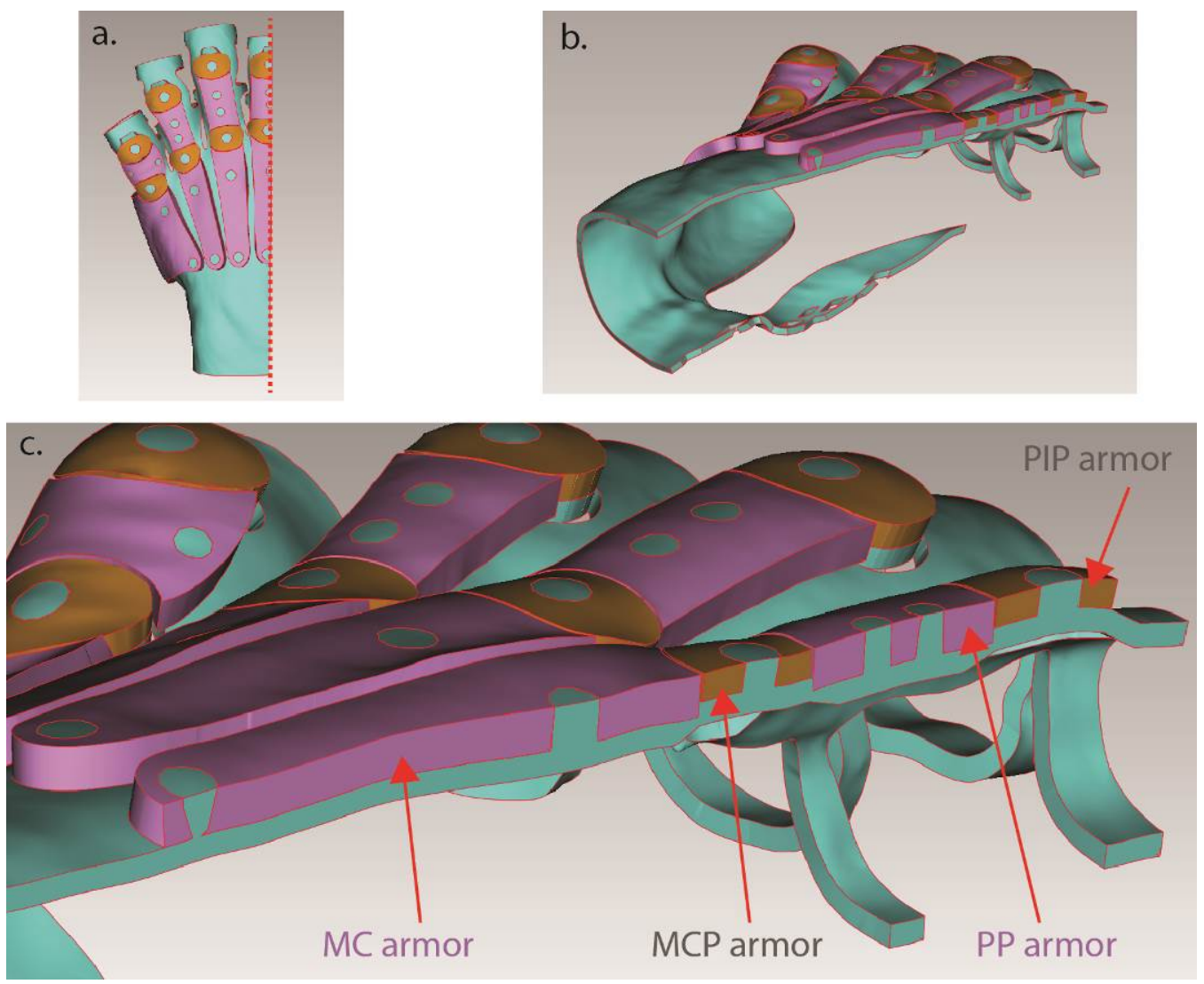

Figure 8: Characteristic 2 and 3. Figure a: Cross-section cut origin; b. side view of cross-section. C. larger cross-section, showing the difference in metacarpal (MC) and proximal phalanx (PP) armor separated with metacarpophalangeal (MCP) and proximal interphalangeal (PIP) joint armor

Characteristic 3. The MCP joints of the fingers can tolerate more hyperextension and therefore the connecting components between the PIPjoints and the metacarpals do not lock when full extension is achieved but are connected by flexible material (Figures 3 and 4). This allows the player to retain hand mobility. The MCP joints of the fingers should allow freedom of movement such as abduction and extension for span grip and adduction and flexion for a closed fist. 


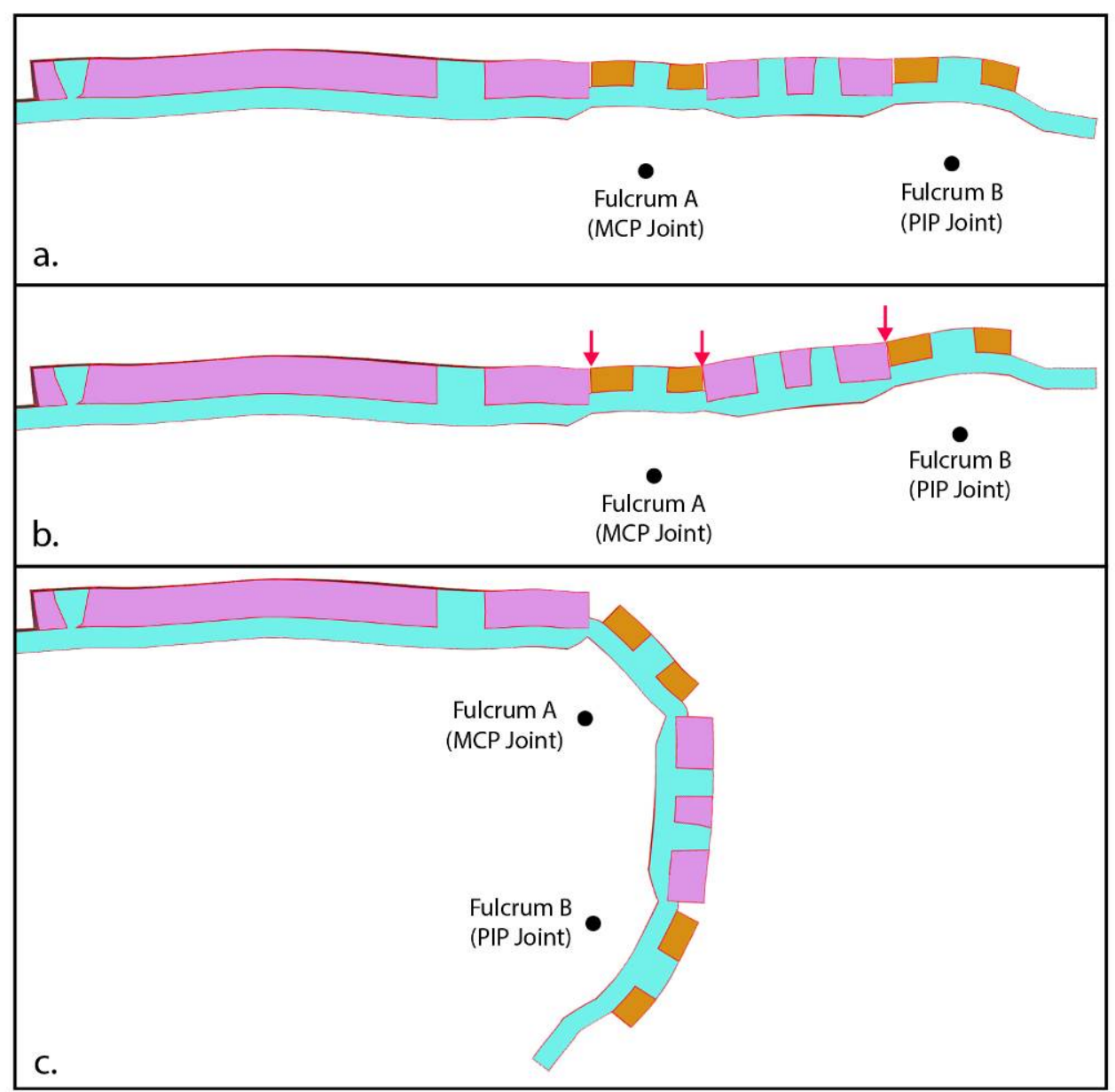

Figure 9: Characteristics 2 and 3 - cross-sections showing geometry and how it aims to enable flexion whilst preventing hyperextension. a: Standard position. b: Attempted hyperextension with collision points marked with red arrows. c: Enabled flexion at joints, as a result of disconnected armor plates and flexible NinjaFlex glove. $\mathrm{MCP}=$ metacarpophalangeal, $\mathrm{PIP}=$ proximal interphalangeal

Characteristic 4. Flexibility between each component of rigid material over each finger metacarpal allows the player to change the shape of the arches of the hand which is essential when handling objects; mimicking the role of the inter-metacarpal ligaments. The rigid components offer external protection to each metacarpal which are susceptible to injury in hurling ${ }^{11}$ (Figure 5). 


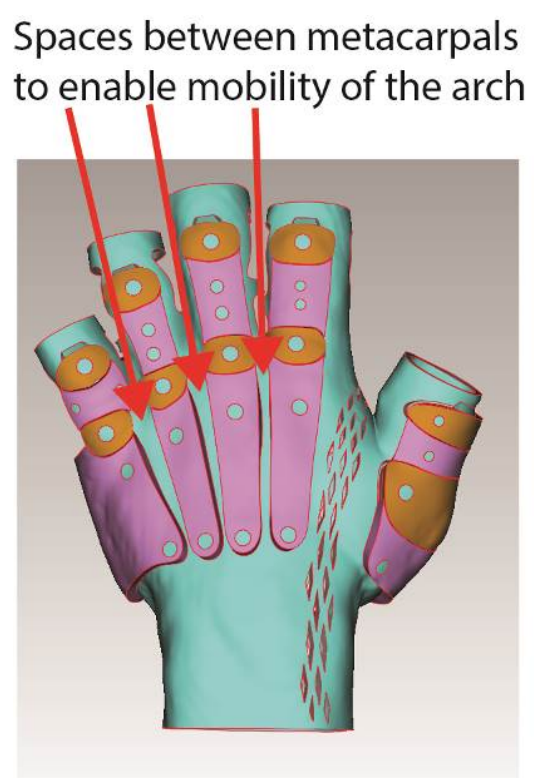

Figure 10: Characteristic 4

Characteristic 5. The metacarpal of the little finger had rigid material over the dorsal aspect and extending to the ulnar border of the bone (Figure 6). Like the first digit, the fifth digit is more vulnerable to injury at the border of the hand ${ }^{13}$.

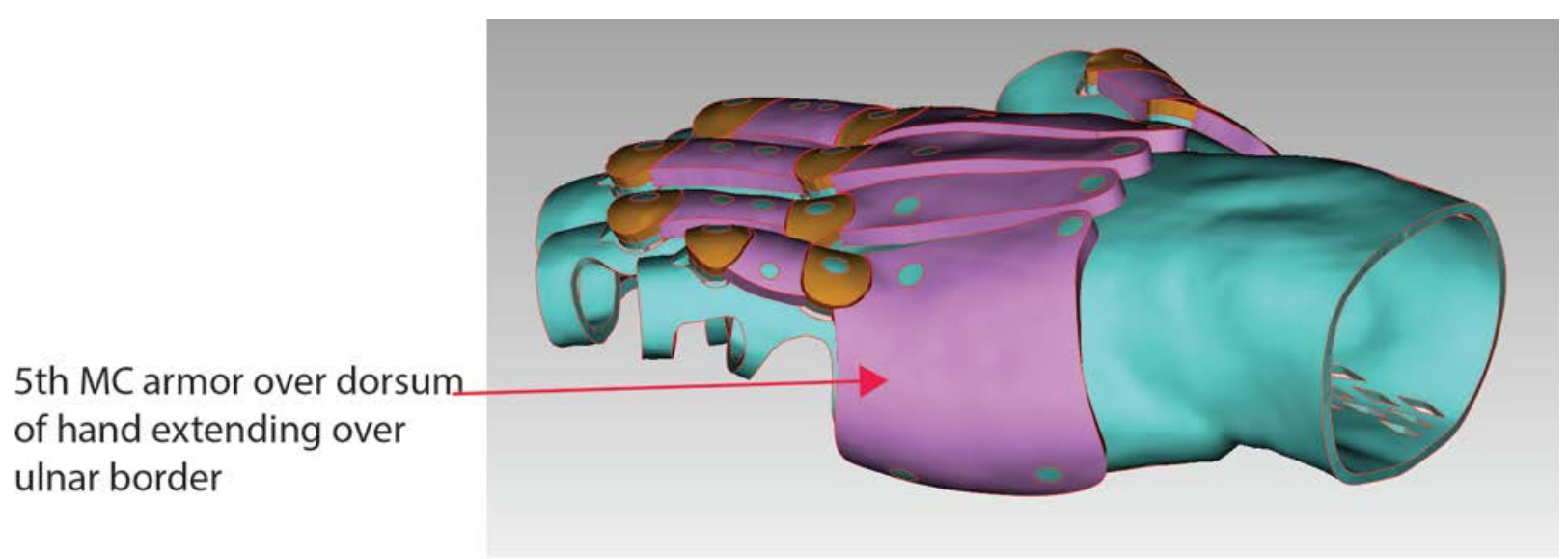

Figure 11: Characteristic 5. $\mathrm{MC}=$ metacarpal 


\subsubsection{Trial and questionnaire}

Several months prior to meeting the players, the Club Committee was provided with the participant information sheet for circulation. On the initial visit to the Club, players who met the study criteria were informed again on the study process via written and verbal information and written, informed consent was obtained. On this visit, recruited players required a 3D scan to be made of each their catching hands. Removable adhesive $5 \mathrm{~mm}$ dots were placed on each joint on the hand to both the volar and dorsal aspect. A mobile rig was devised to position the players' hand so a $360^{\circ}$ scan could be completed. This was completed using the 3D Systems Sense 3D Scanner (Figure 7), connected to an HP Ultrabook (Windows 7 64bit, i5,-4300U, 1.90GHz, 8GB RAM). This enabled the production of a bespoke, 3D-engineered hurling glove for each player based on the design specification, as the scan data helped inform on a custom fit specific for each participant. Using this scan data, a CAD model of each glove was made. Once each design was complete, the CAD models were sent to a Makerbot Replicator 2 3D Printer. 


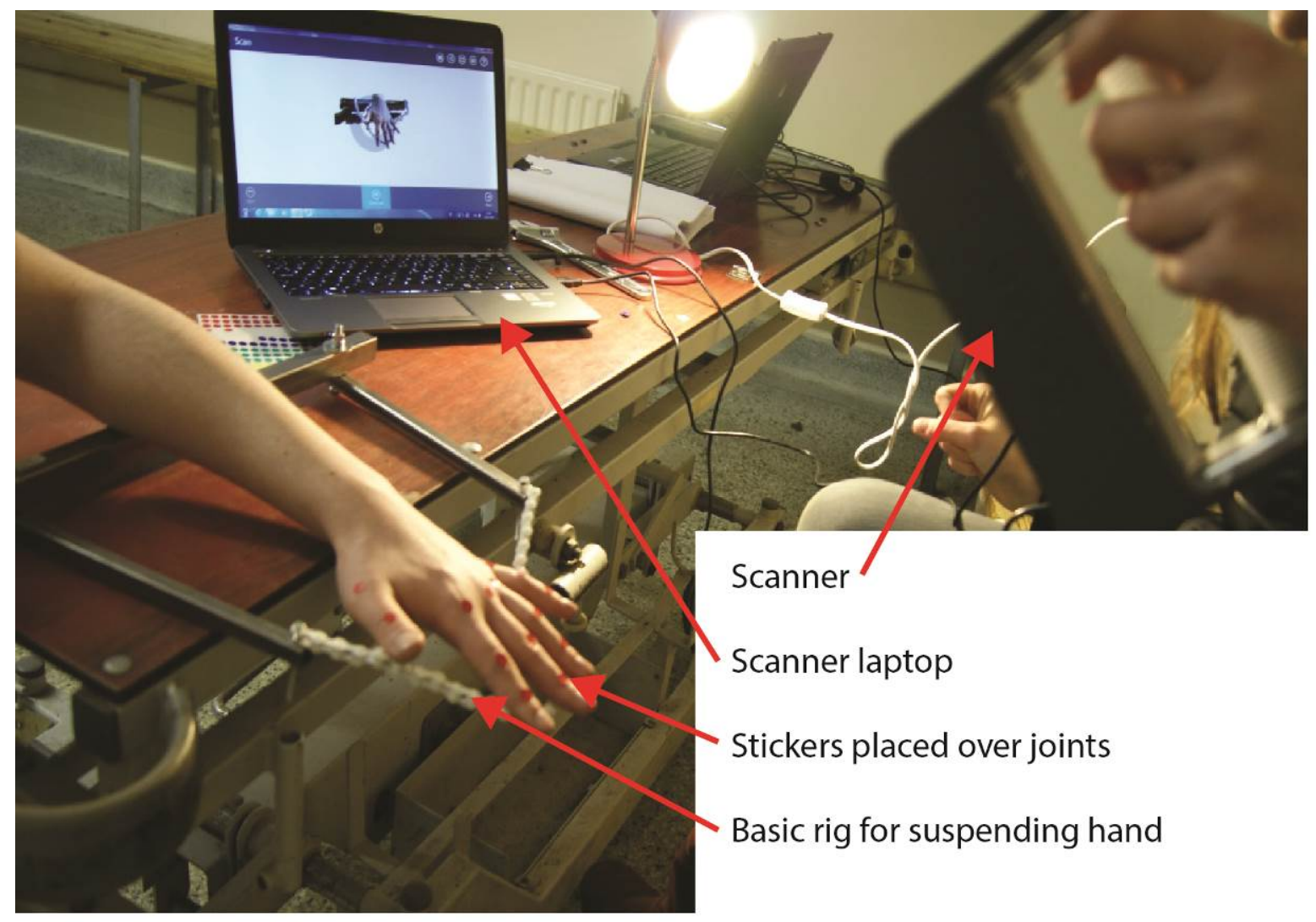

Figure 7: 3D Systems Sense scanner and equipment setup for scanning hands

Armored parts were made with PLA, whilst the main glove was made with Ninjaflex. Upon completion of the 3D print builds, the gloves and armor needed finishing. The Ninjaflex gloves were cleaned up with scissors, a scalpel and a Dremel power tool for smoothing. The PLA armor was cleaned up with the Dremel tool to smooth the surface of the gloves.

Each player was provided with their glove on a second visit to the Club by the hand therapist and the designer. At the start of the session, each player was instructed on how to put on and take off their glove and to ensure there were no issues with the fit. They were also advised that if they experienced any pain or discomfort that they were to remove the glove immediately and to notify the investigators. Feedback was gathered during one session from each participant who were asked to complete a questionnaire about the glove. 


\section{RESULTS}

\subsection{Concept Development}

Nine 3D-engineered hurling gloves were produced (Figure 8). There were no issues with initial fitting of the gloves on any players. Figure 9 illustrates a player catching the slíotar with a glove on.

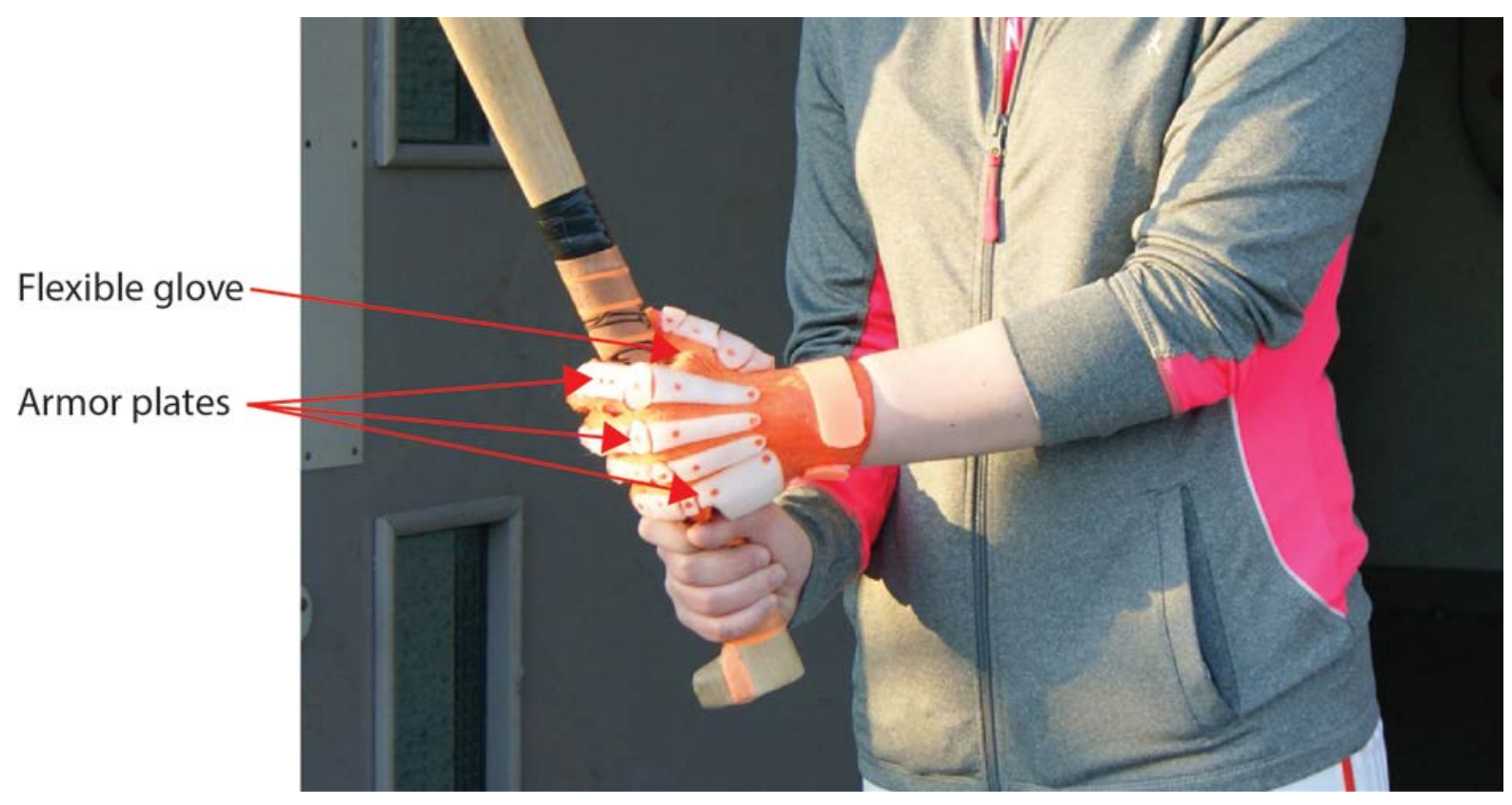

Figure 8: 3D-Printed Hurling Glove

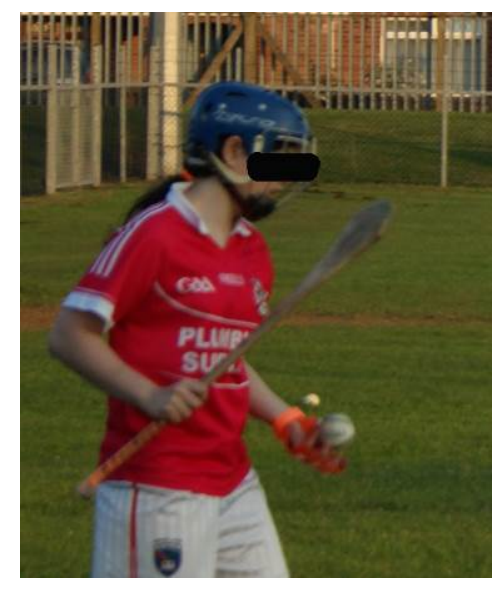

Figure 9: Catching a slíotar with glove on 
Nine players were recruited, one of which was female. The mean age of the players was 32 (SD \pm 9.35 ). Six players were right handed. For two players their "catching hand" was their dominant hand (both were left handed) and one player caught with their right hand (also left handed). Only one player reported no history of hand trauma due to participation in hurling. All reported that they used gloves for protection except for the female player. The average years playing this sport was 19.6 years (SD \pm 10.8$)$. Seven of the players reported having at least one hand injury in the past due to participation in hurling. During the course of the trial, one player reported that the finger components of the glove started to chafe the fingers with motion after a period of use. Therefore use of the glove was immediately stopped.

The three themes of comfort, performance and protection of the glove were explored in a questionnaire. As this feasibility study had a small sample size, descriptive statistics are provided only (Figures 10-12). A four-point Likert-type questionnaire was used to force positive or negative answers. Open questions were also used for more details of the players' views.

\subsubsection{Comfort}

Players were asked: "How would you rate the comfort of the glove you tried today?" Most responses were negative on comfort. The mode response was "Poor". Content analysis of the open questions on comfort indicates that the material was uncomfortable during motion. One player wrote: "Bit tight and rough on the back of the hand. Limited flexibility of fingers. Unable to fully bend." This was a recurring theme in the open questions. The material used to produce the under-armor, while flexible, does not have the property of 
elasticity. This property would maximize comfort as the hand changes shape from extension to flexion. While the responses were mostly poor on comfort, one player did comment that the glove was, "a good fit". As observed by the researchers, all the gloves initially fitted well though issues with comfort arose with hand motion during play i.e. catching and gripping. One player commented: "Good wrist support and fit to hand. Material too restrictive on movement".

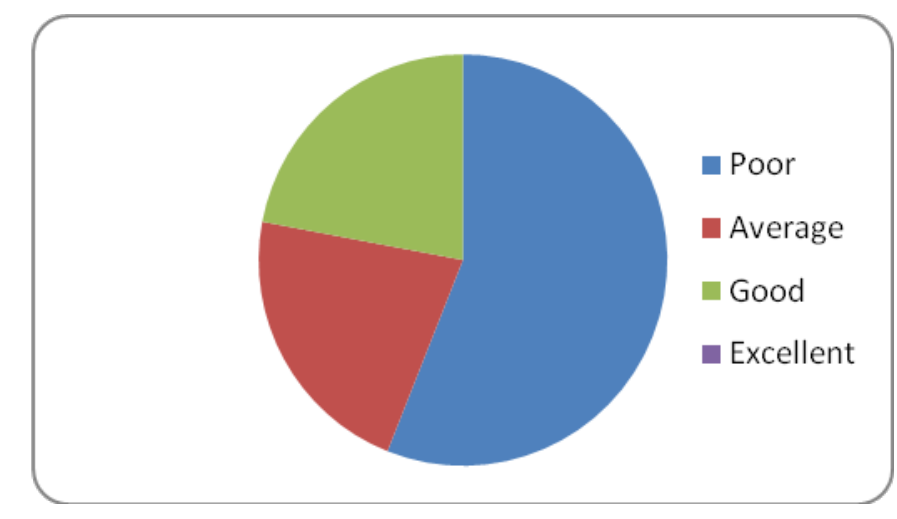

Figure 10: Player rating of glove comfort

\subsubsection{Performance}

Players were asked four questions: two questions on catching and two questions on gripping the hurl. The questions were as follows: "How much did the glove aid your ability to catch the slíotar?", "How much did the glove impair your ability to catch the slíotar?", "How much did the glove aid your ability to grip the hurl?", "How much did the glove impair your ability to grip the hurl?"

No players indicated that the glove enhanced performance. The mode response if the glove aided catching was "Not at all" and if it impaired catching was "A lot". In terms of gripping the hurl, the players' mode response was that it impaired grip "A lot" and it did not aid grip. All the players make reference to the restrictions imposed by the thumb component of the glove during play. Examples of some comments are as follows: "Material 
wasn't flexible enough, thumb was hugely restrictive. Glove was heavy". "The thumb was too restricted". "The thumb is a major factor in catching and securing the ball. Could not use thumb". One player made a positive comment on the design of the finger components of the glove: "The way the glove flexes around the fingers works very well".

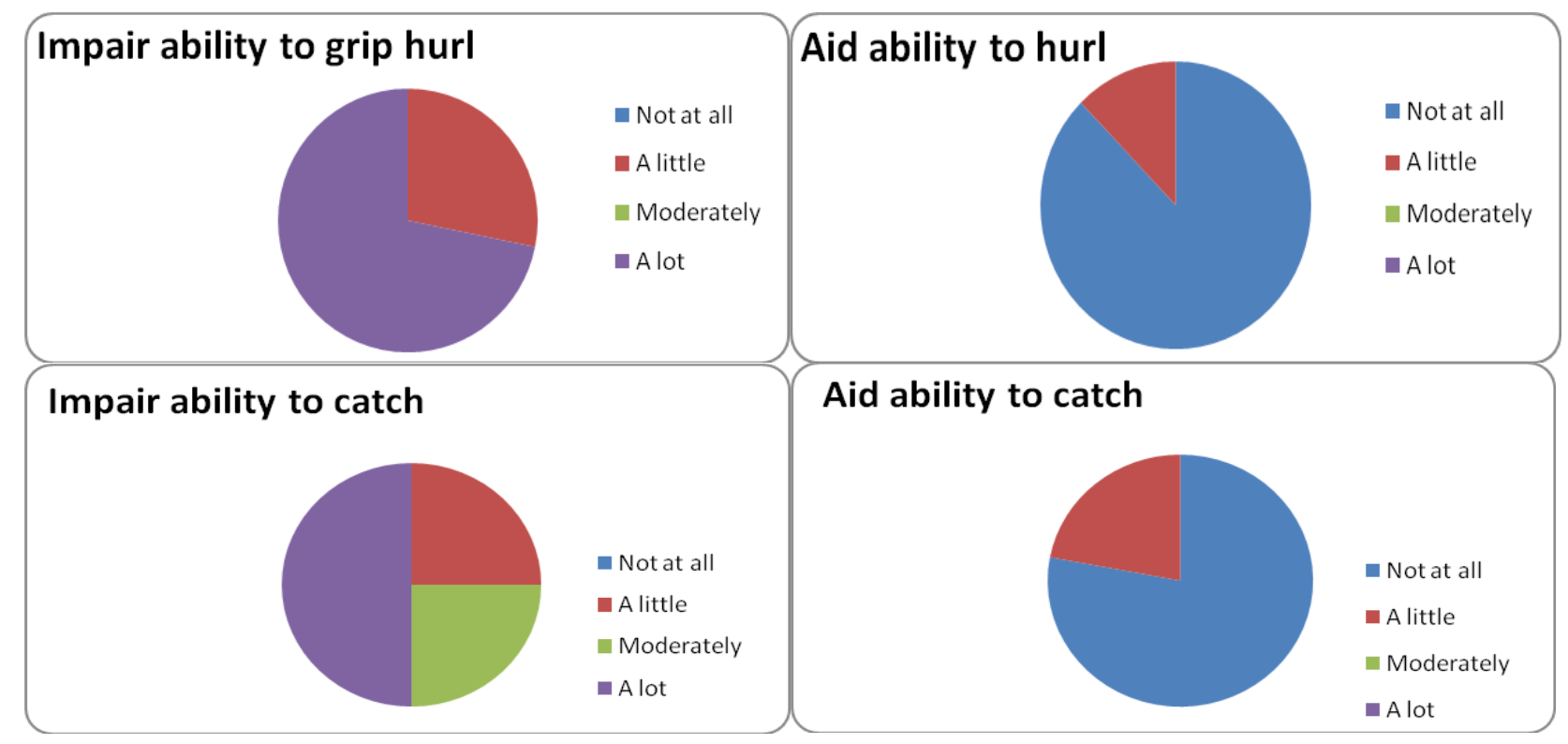

Figure 11: Player rating of glove performance

\subsubsection{Protection}

Players were asked: "How would you rate the level of support the glove offered your hand?" This consisted of three parts which considered protection when catching, to the back of the hand and overall. The mode response on the protection offered by the glove when catching was "None", to the back of the hand "A lot" and overall "Average". Content analysis illustrates that the players found the glove offered support to the dorsal aspect of the hand. Examples of this includes: "Offers protection from contact with opposition hurl" 
and "Material would support impact". However the players identified that the protection offered outweighed the need for balance between performance, protection and comfort: "Maybe would protect hand but didn't help when playing" and "Too much protection". One player suggested how to improve the glove design: "Maybe where the glove grips the finger should be a softer material".

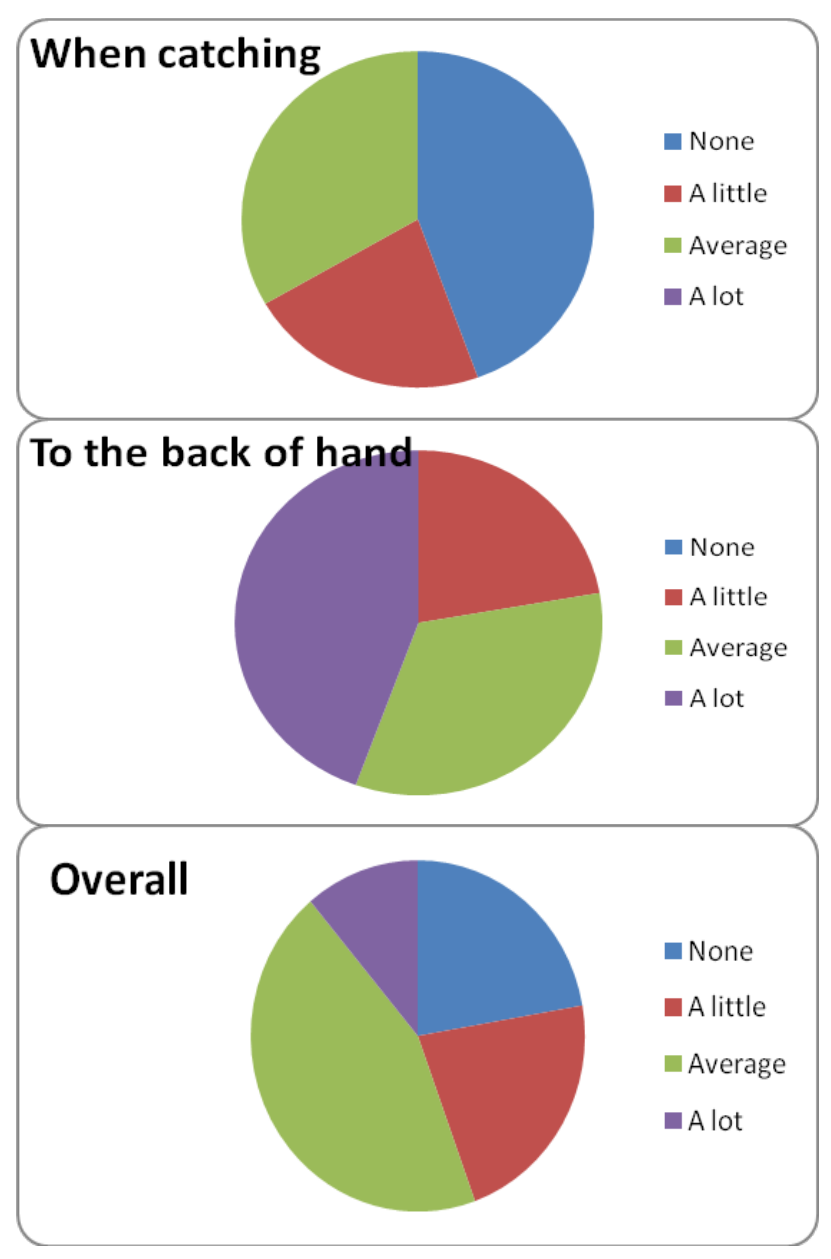

Figure 12: Player rating of glove protection

\section{DISCUSSION}

A 3D-engineered glove was produced for the sport of hurling. The main premise of the glove was to prevent injuries commonly associated with this sport. Prototypes were trialed with a small cohort of hurling players. Results from the questionnaires indicate that the glove offered protection but was not comfortable and it also was a barrier to performance 
in play. Content analysis of the open questions indicates that the material used did not offer enough flexibility to offer adequate comfort and performance. This was particularly noted by the players to the thumb component. The material used to produce the glove under-armor was NinjaFlex. Hurling has a high incidence of hand injuries ${ }^{8-10}$ and a low level of player compliance in wearing protective gloves ${ }^{9}$. The feedback from the players in this study implies that soft materials would enhance performance and comfort.

NinjaFlex, while flexible, does not offer the elastic properties necessary to move in sync with skin mobility that occurs with joint range of motion. Further, the use of PLA to act as an armored layer may have further impeded the flexibility of the NinjaFlex material. To a degree these results were not unexpected as the limitations with the evolving technology of AM were known in advance of the study. However, the successful production of bespoke gloves for a small cohort of players allowed the researchers to evaluate the prototypes in their low-fidelity states.

One limitation of this study was that a small cohort was involved. While this was adequate for the purposes of producing a first prototype, anonymity of each player was difficult to control. For example, when collating the questionnaires it was easy to identify players from demographic data such as age and gender. This may have yielded restrained responses on the questionnaires. Further disadvantages of a small cohort would be the difficulty in generalizing the results to the wider population of hurling players.

From a technical point of view, there were many weaknesses using the chosen 3D printing system which could be optimized to offer a more efficient workflow. A single extruder 3D printer was used. A consequence of this was that the glove and the armor had to be made in separate builds (Figures 13 and 14 respectively), as the chosen 3D Printer only had one extruder so could therefore only print one material at a time. This meant that assembly of armor components (PLA) to the glove (NinjaFlex) was necessary after both the glove and armor were printed. Build time was also a limiting factor; glove builds ranged from 20 
hours (Figure 13) through to 33 hours; this was due to the variation in the size of hands. In retrospect, there was little need to print beyond the thumb metacarpophalangeal joint to span over the PIP joint, as this hindered players' performance. As a result, the build would have been faster without printing this area. The clean-up process of the parts was also very time-consuming, taking approximately 2 hours to remove support material for the Ninjaflex glove and another 90 minutes to sand down sharp edges on the armor.

Whilst it would be helpful to have separate components for armor (as proposed) so that individual parts could be replaced if one aspect gets damaged, this did pose an immediate weakness with regards to the integrity of the glove and the ability to keep armor attached to the gloves. From previous prototypes it was anticipated that the attachment of armor using two pins would suffice, but in retrospect an additional method of attachment would be preferred. The protective property and tensile strength of PLA was not assessed in this study but the material was chosen due to its rigid characteristics. 


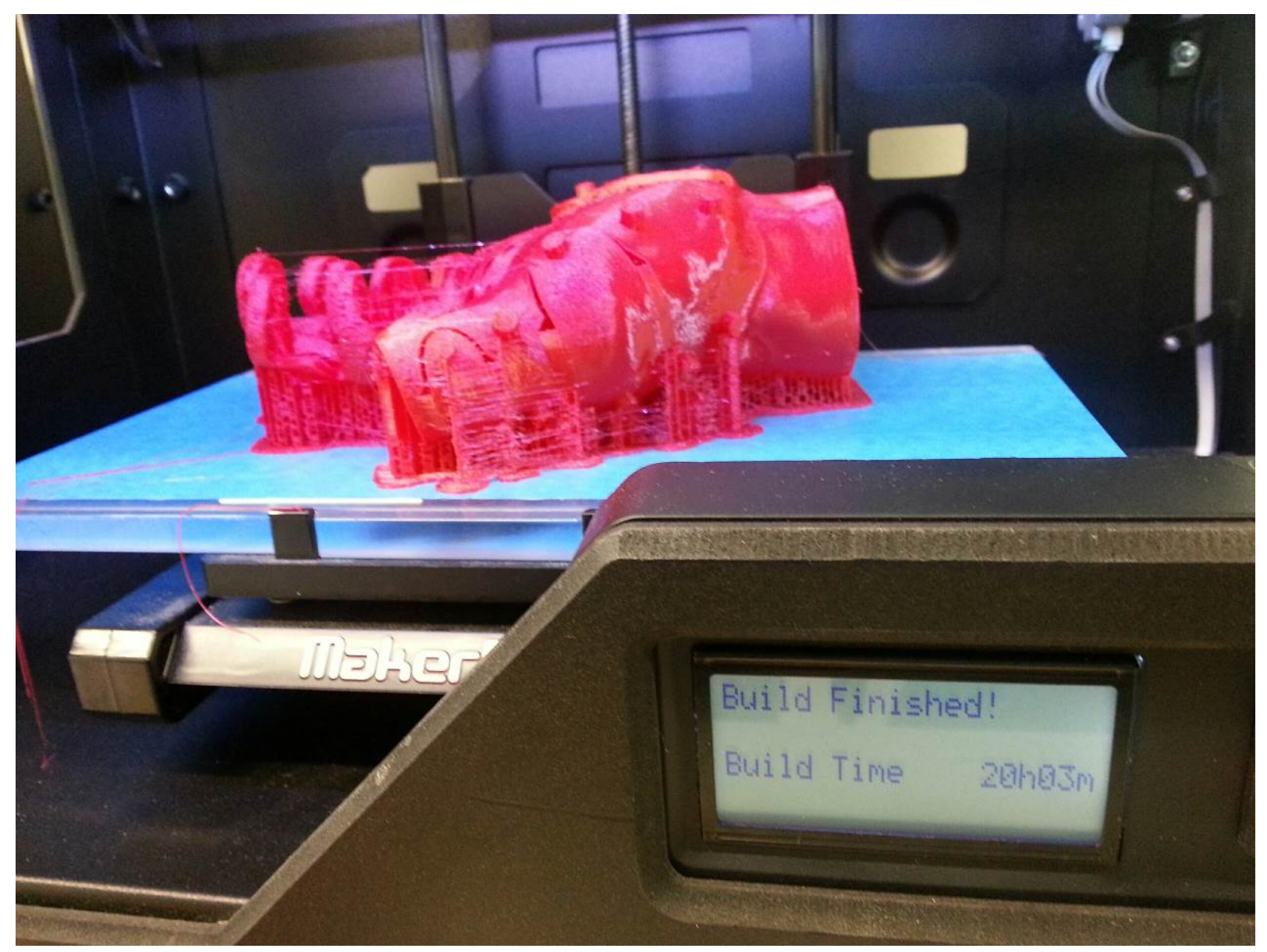

Figure 13: Printed glove, using NinjaFlex 


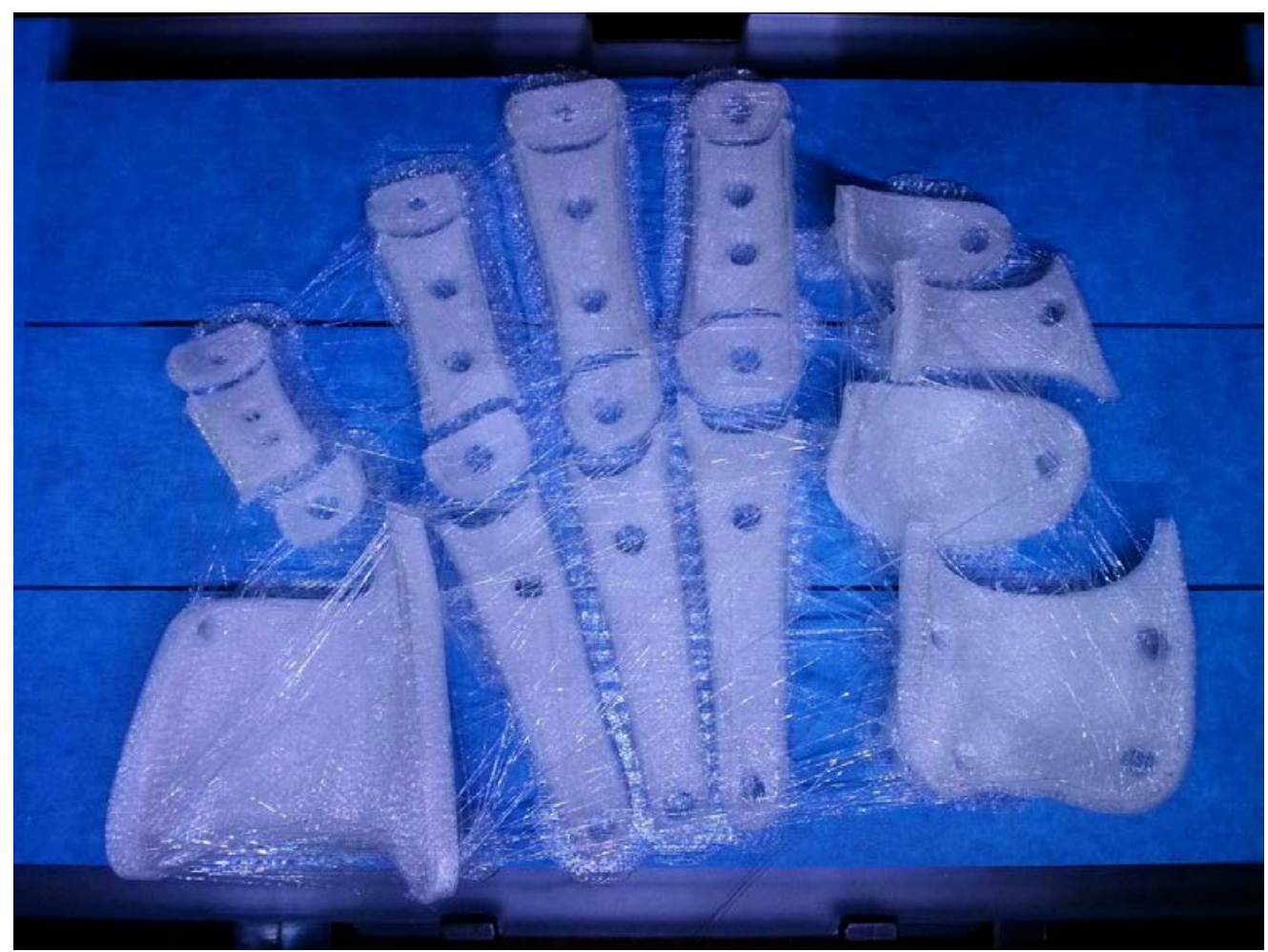

Figure 14: Plan view of the printed armor

Numerous design improvements were identified as a result of the study. For example, it became apparent that coverage of the palm with Ninjaflex should have been significantly reduced; one participant requested a pair of scissors and adjusted the fit themselves midway through the evaluation study in an attempt to provide a better fit, by removing the additional feature over the palm. 


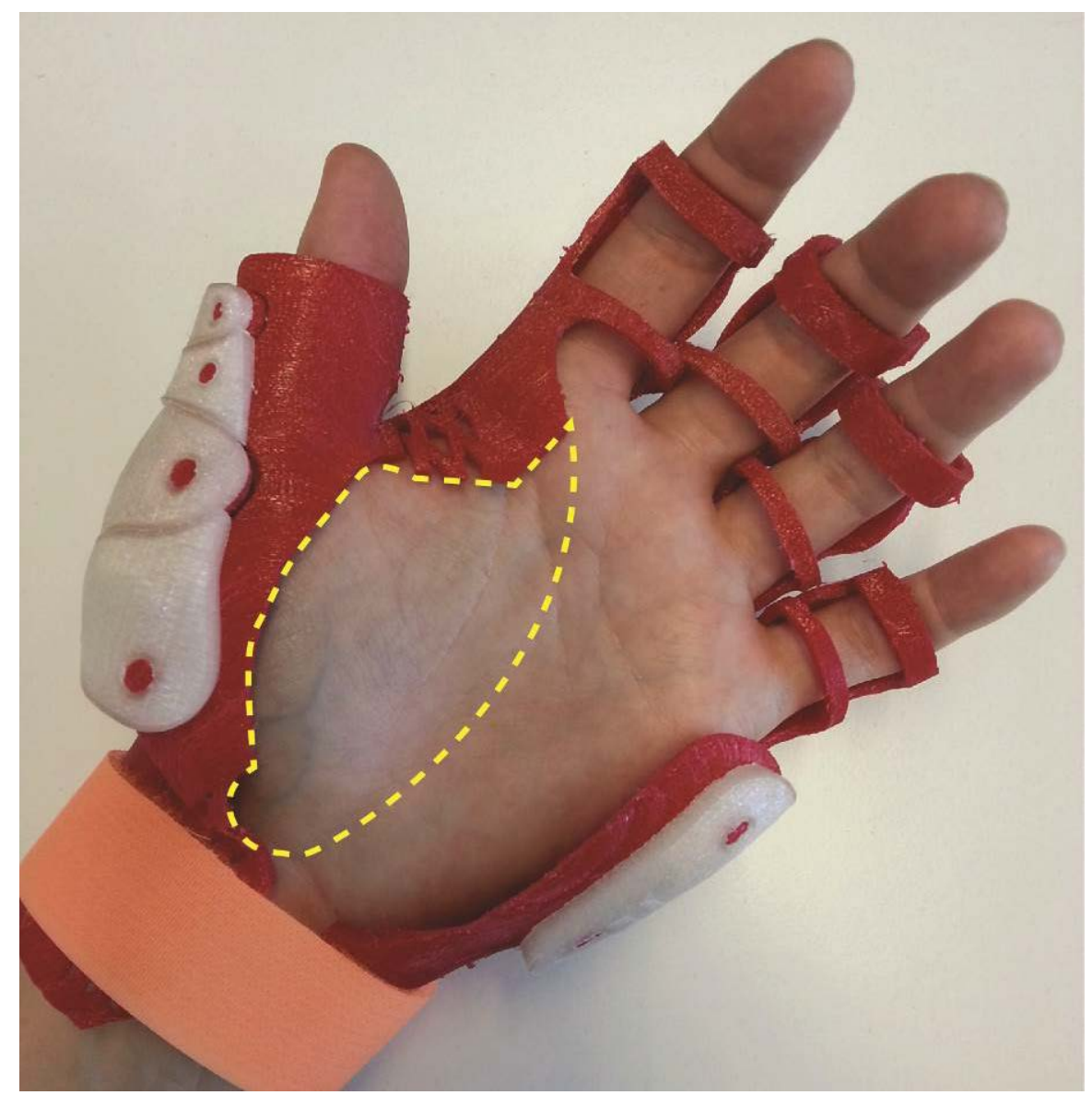

Figure 15: Trimmed palmar region by participant, shown with yellow hatched line

In addition to improvements on fit; the glove geometry could have been offset in CAD software to give additional space between the glove and the skin. It is uncertain at this point as to the most appropriate offset distance that would be needed, but this could form future studies, to ensure that swelling during exercise is accommodated. It is suspected that this may have been why many found the gloves uncomfortable, but this would need further research to explore in more detail.

Using a four-way stretch fabric would change shape with the hand through arches of motion and it should not impose thumb and finger range of movement. However this may be at the cost of adequate protection. The production of four-way stretch materials using additive manufacturing is a possibility ${ }^{24}$. Also, strong materials such as graphene and carbon are also being exploited in additive manufacturing ${ }^{25}$. This presents the possibility of 
producing bespoke 3D-engineered sports gloves that have the property of elasticity for performance and comfort, and lightweight armor for protection (graphene characteristic). The literature in this study provides guidance on where best to provide additional protection. Further research should objectively measure the tensile strength offered by materials used to act as armor. Repeated impact testing on such materials using a droptest machine is one method to do this. Another ideal feature in hurling glove design is to expose as much of the palmar aspect of the hand as possible to maximize sensory feedback when handling the hurl and slíotar.

Glove design requires the management of the complex interplay of protection, performance and comfort. One potential method to do this and optimize design could be using biologically inspired algorithms. These computational algorithms apply "a pseudoDarwinian process to evolve good solutions to real-world problems" ${ }^{26}$. This may give guidance on the best materials to use and the general construct of the glove. A report by the Irish Sports Council ${ }^{27}$ indicates that there are approximately 80,000 adults who play hurling in the Republic of Ireland. Based on confidence levels set at $95 \%$ and a margin of error of $5 \%$, a sample of 383 would provide data representative of the population on perceptions of the ideal glove design and feedback on any future glove designs. This study is the first of its kind to present a case report on the use of 3D-engineered sports gloves. Hand therapists are ideally placed to inform industry and designers on sports glove design as experts on hand anatomy, function and rehabilitation. Therefore the potential role of the hand therapist in health promotion and injury prevention should be developed. Currently the International Federation of Societies for Hand Therapy makes no reference to this in its profile of a hand therapist ${ }^{28}$. In this study the focus has been on hurling. However a similar process can be applied to other sports. This requires an exploration of epidemiology studies on each sport to ascertain the prevalence and 
characteristics of hand injuries. Also research into the functional demands of the hand in each sport will help develop the glove design.

\section{CONCLUSIONS}

Sports glove design requires the balance of comfort, protection and performance. Additive manufacturing has the advantage of producing bespoke gloves for the individual player. The technical insights and player feedback gained in this study presents a platform to further refine glove design. A large study focussing on one sport and possibly across a series of sports with an associated high prevalence of hand injuries is necessary to explore their potential in injury prevention. The use of laboratory testing to gauge the protection offered by such gloves would also present objective data on the protective properties. Anthropometric information could also be garnered from data generated using 3D scanners. This would be of interest across industries including healthcare (e.g. inform on the design of "off-the-shelf" orthoses).

\section{KEYWORDS}

Sport, injury, hand, printing, three-dimensional, protective device

\section{ACKNOWLEDGEMENTS}

The authors wish to thank the Southern Health and Social Care Trust Research and Development Committee for funding this research project. Thanks also to staff in the Research Offices in the Southern Health and Social Care Trust and Loughborough University for assistance in preparing for implementation of the project. Special thanks to Sean Treacy's Hurling Club for agreeing to partake in the study and to all the players who had their hands scanned and to those who trialled the glove and provided invaluable feedback. 


\section{REFERENCES}

${ }^{1}$ Atay E. Prevalence of sports injuries among middle school children and suggestions for their prevention. J Phys Ther Sci. 2014;26:1455-1457

${ }^{2}$ Court-Brown CM, Wood AM, Aitken SA. The epidemiology of acute sports-related fractures. Injury. 2008;39:1365-1372

${ }^{3}$ Aitken S, Court-Brown CM.The epidemiology of sports-related fractures of the hand. Injury. 2008;39:1377-1383

${ }^{4}$ de Putter CE, Selles RW, Polinder S, Panneman MJM, Hovius MD, van Beeck MD. Economic impact of hand and wrist injuries: health-care costs and productivity costs in a population-based study. J Bone Joint Surg Am. 2012;94(9):e56 http://dx.doi.org/10.2106/JBJS.K.00561

${ }^{5}$ Murphy JC, O'Mailley E, Gissane C, Blake C. Incidence of injury in Gaelic football: a 4year prospective study. Am J Sports Med. 2012;40(9):2133-2120

${ }^{6}$ Wilson F, Caffrey S, King K, Casey K, Gissane C.A 6-month prospective study of injury in Gaelic football.Br J Sports Med. 2007;41:317-321

${ }^{7}$ O'Rourke KP, Quinn F, Mun S, Browne M, Sheehan J, Cusack S, Molloy M. A comparison of paediatric soccer, gaelic football and rugby injuries presenting in Ireland. Injury. 2007;38:104-111

${ }^{8}$ Dolan P and Connolly J.The civilizing of hurling in Ireland. Sport in Society. 2009;12(2):196-211 
${ }^{9}$ Clark S. The Importance of agrarian classes: agrarian class structure and collective action in nineteenth-century Ireland. Br J Sociol.1978; 29(1):22-40

${ }^{10}$ The Irish Independent. Is hurling the fastest field sport in the world? \{online\}. 2015 Aug 08. Available from: www.independent.ie/storyplus/is-hurling-the-fastest-field-sport-in-the-world31427432.html. Accessed 2015 Dec 11

${ }^{11}$ Crowley PJ, Crowley M. Dramatic impact of using protective equipment on the level of hurling-related head injuries: an ultimately successful 27-year programme. Br J Sports Med. 2014;48(2):147-150

${ }^{12}$ Blake C, O'Malley E, Gissane C, Murphy JC. Epidemiology of injuries in hurling: a prospective study 2007-2011. BMJ Open. 2014; 4: e005059

${ }^{13}$ Falvey E, McCrory P, Crowley B, Kelleher A, Eustace J, Shanahan F, Molloy MG. Risk factors for hand injury in hurling: a cross sectional study. BMJ Open. 2013; 3: e002634

${ }^{14}$ Kiely PD, Ashraff M, O'Grady P, Dawson MJ, O'Beirne JG. Hurling related hand injuries. Int J Care Injured. 2003; 34: 561-563

${ }^{15}$ Bowers al, Baldwin KD, Sennett BJ. Athletic hand injuries in intercollegiate field hockey players. Med Sci Sports Exerc. 2008; 40: 2022-2026

${ }^{16}$ American Society for Testing Materials International, 2012. ASTM F2792-12a. Standard Terminology for Additive Manufacturing Technologies. West Conshohocken, PA. 
${ }^{17}$ Campbell, R.I. Customer Input and Satisfaction. In: Hopkinson, N., Hague, R.M. and Dickens, P.M.eds. Rapid Manufacturing: An Industrial Revolution for the Digital Age. Chichester: John Wiley \& Sons Ltd. 2006. Pp19-38.

${ }^{18}$ Paterson, A.M., Bibb, R.J., Campbell,R.I. and Bingham, G.A. Comparing Additive Manufacturing Technologies for Customised Wrist Splints. Rapid Prototyping Journal, 2014, 21(3), 230-243.

${ }^{19}$ Wong, J. On-Site 3D Printing of Functional Custom Mallet Splints for Mars Analogue Crewmembers. Aerospace Medicine and Human Performance, 2015, 86(10):911-914

${ }^{20}$ Alec. Low-cost, innovative 3D Printed robotic hand exoskeleton to help heal injuries faster \{online\}. 2015, Octover 19. Available from http://www.3ders.org/articles/20151019low-cost-innovative-3d-printed-robotic-hand-exoskeleton-to-help-heal-hand-injuries.html.

${ }^{21}$ Kira. BMW using 3D Scanning and printing to give Team USA a Shot at Paralympic Gold \{online\}. 2016, April 27 ${ }^{\text {th }}$. Available from: http://www.3ders.org/articles/20160427-bmwusing-3d-scanning-and-printing-to-give-team-usa-a-shot-at-paralympic-gold.html

${ }^{22}$ Johnson JW, Culp RW. Acute ulnar collateral ligament injury in the athlete. Hand Clin, 2009; $25: 437-442$

${ }^{23}$ Bindra RR, Foster BJ. Management of proximal interphalangeal joint dislocations in athletes. Hand Clin, 2009;25:423-435 
${ }^{24}$ White J, Foley M, Rowley A. A novel approach to 3D-Printed fabrics and garments. 3D Printing and Additive Manufacturing. 2015; 2(3): 145-149. doi:10.1089/3dp.2015.0019.

${ }^{25}$ Wei X, Li D, Jiang W, Gu Z, Wang X, Zhang Z, Sun Z. 3D Printable Graphene Compsite. Scientific Reports. 2015; DOI: 10.1038/srep11181

${ }^{26}$ Brabazon A, O'Neill M. Biologically inspired algorithms for financial modelling. New York: Springer Berlin Heidelberg, 2006

${ }^{27}$ Irish Sports Council. Ballpark figures: key research for Irish sports policy \{online\}. 2007. Available from:

http://www.sportireland.ie/Research/Ballpark Figures 2008 /Ballpark Figures.pdf Accessed 2017 Feb 06

${ }^{28}$ IFSHT hand therapy practice profile. International Federation of Societies for Hand Therapy. IFSHT hand therapy practice profile \{Internet\}. 2010 \{cited 2016 Jul 12\}. Available from: http://www.ifsht.org/page/what-hand-therapy 